\title{
Literacia e pensamento crítico: um referencial para a educação em ciências e em matemática
}

CELINA TENREIRO-VIEIRA

Universidade de Aveiro

RUI MARQUES VIEIRA

Universidade de Aveiro

\section{INTRODUÇÃO}

Hoje é amplamente aceite o carácter crucial e imprescindível da intervenção da escola na promoção da literacia científica e matemática das crianças e jovens para que todos os cidadãos possam participar activa e adequadamente no planeamento e resolução de problemas e necessidades pessoais, profissionais e sociais, de forma que viabilize o desenvolvimento de modos de vida produtivos, mais justos e democráticos. Com efeito, documentos de referência internacional, de que é exemplo o relatório Science education now: a renewed pedagogy for the future of Europe (Rocard et al.,2007), têm aturadamente frisado a necessidade de uma educação em ciências, tecnologia e matemática capaz de desenvolver ideias e maneiras científicas de pensar e de reforçar a uma cultura baseada em pensamento racional de modo que habilite cada cidadão a viver e trabalhar numa sociedade do conhecimento.

A necessidade de promover, de forma eficaz, uma formação geral dos cidadãos no domínio da ciência e da matemática numa perspectiva de literacia reflectiu-se e continua a reflectir-se em revisões curriculares. De entre as propostas curriculares para o ensino das ciências numa perspectiva de literacia, destaca-se o Project 2061: science for all americans (Ciência para todos) (Rutherford; Ahlgren, 1990) e documentos subsequentes: Benchmarks for science literacy (American Association for 
the Advancement of Science [AAAS],1993) e National science education standards (National Research Council [NRC], 1996).

No contexto Europeu, salienta-se o projecto Beyond 2000: science education for the future (Millar; Osborne, 1998). No caso da matemática, uma das propostas curriculares de maior repercussão surgiu nos Estados Unidos da América como resultado da liderança do National Council of Teachers of Mathematics (NCTM) nos esforços para a reforma da matemática escolar no intuito de promover a literacia matemática dos alunos. O trabalho desenvolvido traduziu-se no documento Curriculum and evaluation standards for school mathematics (NCTM, 1989). A versão actualizada desse documento, Principles and standards for school mathematics (Standards 2000), reitera a ideia de que todos os alunos devem atingir a literacia matemática (NCTM, 2000).

Na senda do ocorrido em outros países, em Portugal, a Reorganização Curricular do Ensino Básico, expressa no Currículo nacional do ensino básico (Ministério da Educação/Departamento de Educação Básica [ME/DEB],2001), está orientada para o estabelecimento de um currículo nacional. No documento "Ciências físicas e naturais - competências essenciais no ensino básico" (idem), é defendida a tese de que o ensino das ciências deve ser visto, em primeiro lugar, como promotor da literacia científica. Isso porque a crescente importância do conhecimento científico exige uma população cientificamente literada, ou seja, uma população de seguir debates científicos e envolver-se nas questões que a tecnologia coloca, quer para eles como indivíduos, quer para a sociedade como um todo.

Na mesma linha, a educação matemática deve ajudar a desocultar a presença da matemática na sociedade, em ligação com diferentes áreas de actividade humana, promovendo a formação de cidadãos participativos, críticos e confiantes nos modos como lidam com a matemática para analisar e resolver problemas, raciocinar e comunicar (idem).

Não obstante os esforços desenvolvidos em nível de (re)estruturação dos currículos, estudos realizados têm evidenciado o fracasso das aprendizagens de e sobre ciências, tecnologia e matemática. Apesar de a literacia científica ser comummente associada à compreensão de conceitos científicos decisivos, de processos de investigação, da natureza da ciência e ao desenvolvimento de atitudes e de capacidades de pensamento necessárias à tomada de decisões racionais e informadas sobre questões baseadas na ciência e na tecnologia, resultados de investigação têm evidenciado que os alunos, por norma, não desenvolvem tal compreensão, atitudes e capacidades, na sequência do seu envolvimento com a ciência escolar (Bell et al., 2003).

Congruentemente, o estudo Europeans, science and technology (Comissão Europeia, 2005) relata que somente $15 \%$ dos europeus estão satisfeitos com a qualidade das aulas de ciências na escola. $\mathrm{O}$ facto das aulas de ciências não serem suficientemente apelativas é apontado como causa primeira do declínio do interesse pela ciência e pelo prosseguimento de carreiras científicas. Também, o relatório da Organização para a Cooperação e Desenvolvimento Económico (OCDE) (2006), 
"Evolution of student interest in science and tecnology studies", identifica as metodologias de ensino como explicações para o desinteresse dos alunos pela ciência.

No caso português, é ainda de destacar os resultados insatisfatórios dos alunos portugueses no estudo de avaliação internacional da literacia: o Programme for International Student Assessment (PISA). No primeiro ciclo de avalição do PISA (2001), os resultados médios dos alunos portugueses foram inferiores aos obtidos, em média, no espaço da OCDE (Ramalho, 2001). No PISA 2003 (segundo ciclo), em todos os domínios avaliados - leitura, matemática, ciências e resolução de problemas -, os alunos portugueses de 15 anos tiveram um desempenho modesto, uma vez comparado com os correspondentes valores médios dos países do espaço da OCDE (Ramalho, 2004). A mesma tendência regista-se nos resultados relativos ao ciclo do PISA 2006 (Pinto-Ferreira; Serrão; Padinha, 2007).

Inverter ou, pelo menos, procurar minimizar essa situação obriga a perspectivar a formação de professores num quadro de promoção da literacia crítica em ciências e em matemática. Até porque não é expectável que os futuros professores fomentem a literacia científica e matemática crítica dos seus alunos se eles próprios não se sentirem confiantes, incitados e desejosos por alcançar níveis sucessivamente mais elevados de literacia científica e matemática.

A questão da formação de professores assume, pois, importância crucial, porquanto é dos professores e, em particular, da sua formação que depende grandemente a promoção da literacia matemática e da literacia científica crítica dos seus alunos. Uma preocupação basilar, a este nível, prende-se com o desenhar linhas orientadoras para a formação de professores de modo que viabilize o desenvolvimento de uma educação em ciências e em matemática numa perspectiva de literacia matemática e científica crítica. Para tal, é essencial e de interesse em si mesmo estabelecer referenciais acerca da literacia científica e matemática. Como sublinha Kemp (2002), sem uma ideia clara do que se entende por literacia científica e por literacia matemática, a mudança a introduzir na educação em ciências e em matemática torna-se, na melhor das hipóteses, uma noção vaga (DeBoer, 2000). O processo de clarificação e operacionalização dos conceitos requer reflexão e revisão constantes (Harlen, 2002).

Nesse enquadramento, em conjugação com o facto de o pensamento crítico emergir como proeminente e estreitamente ligado à literacia científica e matemática (Brewer, 2008), importa clarificar perspectivas e evidenciar pontos de convergência, zonas de confluência entre pensamento crítico, literacia científica e literacia matemática. Tal poderá ajudar não só a rever, ponderar e potenciar orientações curriculares e práticas de ensino e de aprendizagem, mas também a equacionar a problemática da formação de professores.

Decorrente do exposto, o presente artigo centra-se em estudos realizados pelos autores Vieira e Tenreiro-Vieira (2009) e Vieira, Tenreiro-Vieira e Martins (2010), com a finalidade de conferir clareza e inteligibilidade a esse campo, procurando estabelecer um referencial que ajude a melhor situar e compreender os conceitos de literacia científica, literacia matemática e pensamento crítico e que 
possa ser usado para produtivamente orientar a formação de professores e a educação em ciências e em matemática das crianças e jovens. De um modo mais específico, o estudo tem como objectivos:

1. Analisar diferentes perspectivas conceptuais acerca da literacia científica, da literacia matemática e do pensamento crítico;

2. Relacionar os conceitos de literacia científica, literacia matemática e pensamento crítico, evidenciando conexões entre eles; e

3. Fazer emergir e desenhar um quadro de referência que ajude a melhor situar e compreender os conceitos de literacia científica, literacia matemática e pensamento crítico e que possa ser usado para produtivamente orientar a formação de professores, a produção de recursos didácticos, bem como ponderar e potenciar orientações curriculares e práticas de sala de aula.

Com efeito, o referencial aqui apresentado pode ser usado para ajudar professores e futuros professores de ciências e de matemática a desenvolver visões mais amplas acerca da literacia científica, literacia matemática e pensamento crítico, apropriando-se compreensivamente de referenciais teóricos, essenciais para a aç̧ão sistemática e intencional, com o propósito explícito de promover a literacia crítica dos alunos. Esse referencial configura-se como um suporte ao desenvolvimento de materiais didácticos e de práticas pedagógico-didácticas promotoras da literacia crítica, porquanto apoia na selecção e operacionalização de actividades e estratégias de ensino e de aprendizagem para os alunos mobilizarem grandes ideias e explicações matemáticas e científicas, disposições e capacidades de pensamento crítico, explícitas naquele referencial, na tomada de decisão, na resolução de problemas pessoais, profissionais e sociais e na intervenção racional e esclarecida.

\section{LITERACIA CIENTÍFICA, LITERACIA MATEMÁTICA E PENSAMENTO CRÍTICO: CONEXÕES E EMERGÊNCIA DE UM REFERENCIAL}

Nas últimas décadas, a expressão "literacia científica" entrou definitivamente no discurso de educadores, formadores e políticos. A literacia científica tem sido apontada e reconhecida como a meta primeira da educação em ciências na escola. Não obstante essa ampla concordância, não há consenso quanto ao significado do termo "literacia científica". A expressão tem sido usada com múltiplos significados e interpretações que reflectem diferentes quadros de referência sobre a literacia científica. A diversidade de perspectivas repercute-se inclusive nas designações usadas, porquanto na literatura da especialidade se encontrem expressões como "compreensão pública da ciência", "cultura científica", "literacia científica" e ainda "alfabetização científica".

"Literacia" é o termo mais usado nos Estados Unidas da América, enquanto compreensão pública da ciência é a designação mais usada em países anglo- 
-saxónicos. Em países francófonos abundam os vocábulos "alfabetização científica" e "cultura científica", este o adoptado pela Organização das Nações Unidas para a Educação, a Ciência e a Cultura (UNESCO). Similarmente, para salientar que a matemática capaz de ajudar cada cidadão a lidar de forma eficaz com os aspectos quantitativos da vida não se restringe ao conhecimento de factos e ao domínio de técnicas de cálculo, têm sido usados termos como: "literacia matemática", "literacia quantitativa" "literacia numérica", "numeracia" e "competência matemática”. Apesar de todos esses termos estarem associados a uma visão do ensino da matemática como um processo de desenvolvimento do poder matemático das crianças e dos jovens para lidar com uma sociedade impregnada de informação quantitativa, cada um deles encerra nuances e conotações que importa captar.

Analogamente, não obstante o relevo que continua a ser atribuído ao pensamento crítico, não há um acordo claro sobre o significado da expressão, denotando-se, inclusive, o uso indiscriminado de termos como: "pensamento crítico", "raciocinar" " "capacidades cognitivas de nível elevado". A diversidade de perspectivas acerca do pensamento crítico, em conjugação com a multiplicidade de termos associados ao pensamento crítico, reforça a necessidade de clarificar o(s) conceito(s) de pensamento crítico. Tal clarificação do(s) conceito(s) é necessária para lidar com outras questões como, em particular, o delinear de linhas orientadoras para a formação de professores e para o ensino e a aprendizagem das ciências e da matemática - em foco neste artigo. Decorrente do exposto, de seguida, exploram-se perspectivas de diferentes autores acerca da literacia científica, literacia matemática e pensamento crítico.

\section{LITERACIA CIENTÍFICA}

No decurso do desenvolvimento do conceito de literacia científica, diferentes posições, interpretações e definições têm sido propostas. $\mathrm{O}$ trabalho de Pella, O'Hearn e Gale (1966 apud Laugksch, 2000) representa uma das primeiras tentativas de introduzir uma base empírica para a definição de literacia científica. Esses autores, com base em uma revisão de artigos, concluíram que os atributos privilegiados incluíam a compreensão da(s): (1) inter-relações ciência-sociedade; (2) dimensão ética do trabalho dos cientistas; (3) natureza da ciência; (4) diferenças entre a ciência e a tecnologia; e (5) inter-relações ciência-humanidades e de conceitos científicos base.

No quadro da clarificação do conceito de literacia científica, outra das tentativas pioneiras é atribuída a Shen (1975 apud idem). O autor sugeriu, de forma pragmática, três categorias de literacia científica:

1. Literacia científica prática: conhecimento científico útil para viver nas sociedades modernas (para, por exemplo, resolver problemas práticos relacionados com a saúde e com a alimentação);

2. Literacia científica cívica: conhecimento útil para os cidadãos se envolverem no processo de tomada de decisão sobre questões públicas relacionadas 
com a ciência (por exemplo, saúde pública, protecção ambiental e recursos naturais);

3. Literacia científica cultural: conhecimento que permite apreciar a beleza intelectual do saber científico.

A revisão conceptual e empírica feita por Miller (1983 apud idem) foi marcante no campo da literacia científica, porquanto não só propôs uma definição multidimensional como procurou estabelecer critérios úteis de avaliação da literacia científica. Na perspectiva de Miller, a literacia científica funcional devia ser vista como o nível de compreensão da ciência e da tecnologia necessário para funcionar minimamente como cidadão e como consumidor numa sociedade democrática de cariz científico-tecnológico. Nesse quadro, para o autor, a literacia científica envolve três dimensões relacionadas: a compreensão de normas e do processo de investigação científica (isto é, a natureza da ciência), a compreensão de termos e conceitos base da ciência (isto é, o conteúdo da ciência) e a consciencialização do impacto da ciência e da tecnologia na sociedade (isto é, questões de política científica).

$\mathrm{Na}$ explicitação da sua perspectiva sobre a literacia científica, Arons (1983 apud idem) enfatiza as capacidades de pensamento que a pessoa cientificamente literada deve possuir para resolver problemas e tomar decisões na sua vida pessoal, cívica e profissional. Tais capacidades envolvem: reconhecer que os conceitos científicos são produto da inteligência e criatividade humanas; distinguir observação de inferência; formular e testar hipóteses e formular e responder a questões como: "Por que acreditamos?", "Como sabemos?", "Qual é a evidência para [...]?”.

Uma posição teórica que gerou controvérsia entre os defensores da tese de que a meta primeira da educação em ciências deve ser o promover a literacia científica foi proposta por Shamos (1995). Para o autor, não é verosímil que um indivíduo educado seja totalmente iliterado em ciências; todos têm alguma ideia acerca da ciência, não obstante o facto de tais ideias poderem ser ingénuas. Considerando ser uma supersimplificação assumir que um indivíduo é literado ou iliterado em ciências, o autor defende que o conceito de literacia científica deve ser encarado segundo três níveis de literacia de complexidade crescente.

O primeiro, designado por literacia científica cultural, envolve o conhecimento do léxico e do conteúdo da ciência que permite acompanhar a divulgação da ciência e debates que ocorrem na sociedade. Traduz, na perspectiva do autor, uma posição passiva dos indivíduos perante a ciência. $\mathrm{O}$ segundo nível, literacia científica funcional, é de cariz activo, pois requer que os indivíduos, para além de conhecerem vocabulário científico, sejam também capazes de ler, escrever e comunicar com os outros sobre assuntos públicos que envolvem a ciência. $\mathrm{O}$ terceiro nível, a literacia científica verdadeira, exige que os indivíduos conheçam como se gerou o próprio conhecimento científico e por que é amplamente aceite. A esse nível, o indivíduo deve, ainda, usar capacidades e atitudes científicas.

O NRC (1996, p. 22, tradução nossa), no documento National science education standards, explicita o que deve entender-se por literacia científica: "conhecimento 
e compreensão de conceitos científicos e capacidades de pensamento requeridos para decisões pessoais, para a participação em actividades cívicas e culturais e para a produtividade económica". Para que isso aconteça, é necessário que cada indivíduo seja capaz de: (1) questionar, pesquisar e responder a questões do quotidiano, suscitadas pela própria curiosidade; (2) descrever, explicar e prever fenómenos naturais correntes; (3) interpretar textos de divulgação científica e envolver-se na discussão pública da validade das conclusões neles apresentadas e das metodologias usadas; (4) identificar questões de natureza científica subjacentes a decisões de âmbito local e nacional; (5) assumir e expressar posições fundamentadas em conhecimentos científico-tecnológicos; (6) avaliar informação científica com base na credibilidade das fontes e na validade dos métodos usados para a gerar; e (7) argumentar com base em evidências científicas.

Comum a várias perspectivas, incluindo a expressa pelo NRC, é o considerar que a literacia científica compreende diferentes níveis, o que reflecte uma visão do conceito como envolvendo um contínuo por oposição a uma situação de tudo ou nada. Partilhando essa posição, Bybee (1996) propôs quatro níveis de literacia científica: (1) literacia científica nominal; (2) literacia científica funcional; (3) literacia científica conceptual e processual; e (4) literacia científica multidimensional. Passa-se a explicitar cada um deles.

1. Literacia científica nominal: significa que a pessoa reconhece termos, questões e assuntos científicos, mas possui pouco conhecimento sobre eles; evidencia, com frequência, concepções intuitivas e/ou alternativas.

2. Literacia científica funcional: significa ser capaz de usar vocabulário (termos técnicos associados à ciência e à tecnologia), apropriada e adequadamente, em contextos específicos, para, por exemplo, escrever ou ler um artigo ou acompanhar o sentido de uma notícia.

3. Literacia científica conceptual e processual: significa ser capaz de situar conceitos numa dada disciplina, relacionando-os com conceitos mais abrangentes; o indivíduo é capaz de aplicar procedimentos de metodologia científica para resolver problemas específicos.

4. Literacia científica multidimensional: significa ser capaz de se envolver no questionamento filosófico, histórico e social das disciplinas, compreendendo o papel da ciência na sociedade, bem como os limites e as possibilidades da ciência para a vida pessoal e social.

A visão de Bybee (idem) acerca da literacia científica acentua a dependência da literacia científica do contexto, do domínio e do tópico em apreciação. Assim, um mesmo indivíduo poderá situar-se em diferentes níveis de literacia consoante os domínios científicos considerados. Por conseguinte, o nível de literacia alcançado deverá ser sempre reportado a um dado contexto.

Sublinhando a ideia de que a literacia científica é dependente do contexto e da cultura, SjØberg (1997) defende que só faz sentido falar em literacia científica 
funcional. Nesse enquadramento, para o autor, um conceito válido de compreensão pública da ciência deve reflectir três dimensões:

1. Ciência como produto: o conhecimento científico é reconhecido como uma construção humana, sujeito à mudança e modificação, mas razoavelmente estável e cumulativo.

2. Ciência como processo: a construção do conhecimento científico envolve procedimentos de recolha, análise e avaliação de evidência, bem como procedimentos de resolução de problemas.

3. Ciência como instituição social: a comunidade científica, com os seus valores, normas, ideias, interesses e prioridades, é um elemento importante da sociedade. Uma compreensão da ciência, hoje, é impensável sem alguma compreensão das suas relações com a sociedade.

Na perspectiva de Hurd (1998) e quarenta anos após o seu primeiro artigo sobre o tema, o conceito literacia científica deve reconhecer as mudanças que ocorrem na sociedade e na própria ciência. Tais mudanças constituem um referencial para um conceito de literacia científica que inclua a capacidade de usar o conhecimento científico nas diferentes actividades humanas para o progresso social e económico e para a qualidade de vida. A literacia científica é vista como uma competência cívica requerida para desenvolver um pensamento racional sobre a ciência com respeito a questões e problemas pessoais, sociais, políticos e económicos com os quais cada um se confrontará ao longo da vida, que envolve o ser capaz de alguém que:

1. Distingue teoria de dogmas; dados de mitos; ciência de pseudociências; evidência de propaganda; facto de ficção; conhecimento de opinião.

2. Reconhece a natureza da ciência como evolutiva e tentativa; quando os dados não são suficientes para tomar uma decisão racional; quando uma relação de causa e efeito não pode ser estabelecida; os limites das decisões com base no conhecimento científico e tecnológico.

3. Reconhece que a ciência e a tecnologia em contextos sociais têm implicações em nível ambiental, social, político e económico; a influência da sociedade na ciência e na tecnologia.

4. Reconhece que alguns problemas societais podem ter mais do que uma resposta aceitável; são, em geral, de natureza multidisciplinar, envolvendo também dimensões culturais, éticas e morais; a sua resolução exige intervenções concertadas mais do que acções individuais, e soluções a curto e a longo prazo podem ter respostas diferentes.

5. Sabe como analisar dados e usar conhecimento científico, quando apropriado, para tomar decisões, fazer juízos de valor, resolver problemas e implementar cursos de aç̧ão. 
Com base numa revisão de literatura sobre literacia científica, a OCDE, no contexto do PISA, estabeleceu a sua própria definição de literacia científica (OCDE, 2000, 2003; Harlen, 2001, 2003). Nesse quadro, a literacia científica é definida como a capacidade de usar conhecimento científico para identificar questões e tirar conclusões baseadas em evidência com o propósito de compreender e ajudar a tomar decisões sobre o mundo natural e as mudanças nele operadas por meio da actividade humana.

Assim definida, a literacia científica compreende três aspectos ou dimensões: (1) conteúdo científico, interpretado como grandes ideias e não como factos isolados; (2) processos científicos, entendidos como aç̧ões mentais, e por vezes físicas, usadas na concepção, obtenção, interpretação e uso de evidência; e (3) áreas de aplicação, nas quais são usados os processos e a compreensão de grandes ideias e que tomam a forma de questões baseadas na ciência.

A dimensão conteúdo científico inclui conhecimentos seleccionados de campos centrais da física, química, biologia e ciências da terra e espaço de acordo com critérios de relevância para situações do dia a dia, bem como para a vida futura dos cidadãos e para assuntos nos quais podem ser aplicados processos científicos.

$\mathrm{Na}$ dimensão relativa aos processos científicos, o quadro de referência do PISA 2003 é descrito em termos de três processos base (OCDE, 2003; Harlen, 2003). São eles:

1. Descrever, explicar e prever fenómenos científicos: envolve demonstrar compreensão aplicando conhecimento científico apropriado a uma dada situação, descrever ou explicar fenómenos e prever mudanças.

2. Compreender a investigação científica: inclui identificar questões que podem ser investigadas cientificamente e saber o que está envolvido em tal investigação; identificar ou reconhecer evidência necessária numa investigação científica, como, por exemplo, que variáveis devem ser controladas, que informação adicional é necessária ou que acções devem ser realizadas de modo que dados relevantes possam ser recolhidos.

3. Interpretar evidência científica e tirar conclusões: inclui atribuir significado a resultados científicos como evidência de suporte a determinadas conclusões; avaliar informação científica; comunicar conclusões baseadas em evidência científica; seleccionar e comunicar conclusões alternativas; apresentar razões a favor ou contra uma certa conclusão de dados fornecidos ou identificar assunções feitas para chegar a uma dada conclusão; e reflectir e comunicar as implicações societais de conclusões científicas.

A dimensão áreas de aplicação inclui os contextos e as situações para a aplicação de conceitos e para o uso de processos científicos; envolve assuntos e/ou questões relacionados com a ciência que os cidadãos de hoje e de amanhã precisam de compreender, visando, nomeadamente, à tomada de decisão sobre estes. A título ilustrativo, uma das áreas de aplicação é designada por "Ciência na vida e na saúde", que inclui assuntos como: saúde, doença e nutrição; manutenção e uso sustentável de espécies. 
A literacia científica, tal como definida no quadro da OCDE/PISA, enfatiza o uso de conhecimento científico para tirar conclusões baseadas em evidência. Cada cidadão precisa de saber quando o conhecimento científico é relevante, distinguir questões a que a ciência pode e não pode responder, ajuizar sobre a validade da evidência, tanto em termos da sua relevância quanto em termos do como foi recolhida. A capacidade de relacionar evidência e conclusões é vista como central para todos os cidadãos, de modo que sejam capazes de tomar decisões sobre cursos de acção que afectam a vida no nível pessoal, social e/ou global. É também enfatizada a capacidade de os alunos comunicarem eficazmente, pois, em caso contrário, não terão voz activa nos debates públicos sobre assuntos com uma componente científica.

\section{LITERACIA MATEMÁTICA}

Uma das primeiras definições do termo numeracia surgiu no relatório Cockcroft (1982 apud Steen et al., 2001), sob a responsabilidade do governo britânico, sobre o ensino da matemática. No âmbito desse relatório, o termo "numeracia" implica dois atributos. O primeiro envolve ter à vontade com os números e usar capacidades e atitudes, bem como aplicar conhecimentos matemáticos que permitem a um indivíduo lidar com as exigências práticas da vida quotidiana. O segundo representa a disposição para valorizar e a aptidão para compreender informação apresentada em termos matemáticos.

No contexto da "National Numeracy Strategy" (United Kingdom national literacy and numeracy strategies”, Fullan; Earl, 2002) - iniciativa centralmente concebida e desenvolvida no quadro dos recentes esforços de reforma do sistema educativo inglês -, a numeracia é entendida como uma competência que envolve compreensão do sistema de numeração, domínio de técnicas de cálculo e confiança e à vontade com os números e com medidas. A numeracia também envolve compreensão sobre o como a informação é recolhida e apresentada, bem como disposição e capacidade para resolver problemas numa variedade de contextos.

No âmbito do "Project Numeracy"("The algebraic nature of student's numerical manipulation in the New Zealand numeracy project", Irwin; Britt, 2005) - programa introduzido na matemática pelo ministro da educação da Nova Zelândia e destinado a alunos dos 5 aos 14 anos de idade -, a numeracia é encarada como uma abordagem flexível à resolução de problemas, baseada na compreensão das operações envolvidas na resolução destes. Nesse sentido, um dos propósitos do projecto prende-se com o promover, nos alunos, o sentido do número e das operações. Assim, as experiências de aprendizagem preconizadas envolvem, por exemplo, planear e testar diferentes estratégias na resolução de problemas aritméticos; modelar e resolver problemas usando diversas ferramentas algébricas.

Reportando-se ao trabalho e investigação desenvolvida no King's College, Brown (2000) explicita que o termo "numeracia" é definido como a capacidade de processar, comunicar e interpretar informação numérica numa variedade de contextos. Zevenbergen (2004) usa também o termo "numeracia" perspectivando-o como conhecimento prático e disposição para usar a matemática em múltiplos contextos. 
A numeracia também é a utilização da matemática na resolução de problemas que surgem no contexto do dia a dia.

Steen e seus colaboradores (2001) usam o termo "literacia quantitativa", definindo-o como hábito mental, uma abordagem aos problemas que emprega e promove o uso de conhecimentos de matemática. A literacia quantitativa envolve uma matemática activamente relacionada com o mundo empírico, com a realidade. Nessa óptica, a perspectiva dos autores sobre literacia quantitativa enfatiza a compreensão e utilização da matemática na resolução de problemas com os quais as pessoas se confrontam no quotidiano.

De modo que obtivessem uma visão mais compreensível, Steen e seus colaboradores (idem) procuraram evidenciar os elementos envolvidos no conceito de literacia quantitativa. Tais elementos, relacionados com atitudes, conhecimentos e capacidades, incluem:

1. À vontade na matemática: sentir-se confortável com ideias quantitativas e sentir facilidade na aplicação de métodos quantitativos; sentir confiança na área dos números, utilizando estratégias mentais para estimar, interpretar e verificar outras informações.

2. Sentido do número: compreender os significados dos números, reconhecer a grandeza relativa deles e ter confiança em fazer estimativas e em aplicá-los como medida de algo.

3. Sentido do símbolo: estar à vontade na utilização de símbolos algébricos, ter facilidade na sua leitura e interpretação e conhecer as regras sintácticas a utilizar em frases matemáticas.

4. Matemática contextualizada: utilizar métodos e ferramentas matemáticas em situações em que o contexto fornece significado.

5. Apreciação ou valorização cultural: compreender a natureza e a história da matemática; reconhecer o seu papel na investigação científica e nos avanços tecnológicos e a sua importância na compreensão de assuntos do domínio público.

6. Capacidades práticas: resolver problemas quantitativos que surgem em casa ou no trabalho.

7. Interpretação de dados: desenvolver raciocínios partindo de dados, interpretar gráficos, fazer inferências e reconhecer possíveis fontes de erros.

8. Pensamento lógico: analisar evidência, analisar argumentos, questionar assunções, detectar falácias e avaliar riscos.

9. Tomar decisões: utilizar a matemática para tomar decisões e resolver problemas do quotidiano, encarando a matemática como uma ferramenta poderosa e útil para a vida.

O grupo responsável pelo Mathematics Learning Study (apud Kilpatrick, 2001), para referir e caracterizar a aprendizagem bem-sucedida da matemática, estabeleceu o termo "competência matemática", definindo-o em cinco elementos 
interdependentes que se prendem com a mobilização de conhecimentos, atitudes e capacidades de pensamento. Esses elementos são:

1. Compreensão conceptual: compreensão de conceitos matemáticos, operações e relações;

2. Fluência processual: ser capaz de executar procedimentos matemáticos de forma flexível, precisa, apropriada e eficaz;

3. Capacidade estratégica: capacidade de formular, representar e resolver problemas;

4. Raciocínio adaptativo: capacidade de explicar, justificar e reflectir sobre argumentos matemáticos;

5. Disposição produtiva: confiança na autoeficácia para fazer matemática e inclinação ou tendência para ver a matemática como uma disciplina sensível e útil em múltiplos contextos pessoais, profissionais e sociais.

Na perspectiva de Pugalee e Chamblee (1999), o aluno matematicamente literado deve ser capaz de: construir e alternar entre várias representações (por exemplo: simbólicas, icónicas e pictoriais); compreender a complexidade e natureza de cálculos matemáticos, algoritmos e procedimentos; realizar, com êxito, cálculos e procedimentos; fazer conjecturas; recolher evidência e construir argumentos; tirar conclusões lógicas; identificar padrões e relações na análise de situações; justificar respostas e processos de solução; e resolver problemas. Resolver problemas envolve a mobilização de conhecimentos e capacidades, tais como: elaborar um plano para resolver um problema, monitorar o progresso desse plano e avaliar a aceitabilidade dos resultados.

No quadro de referência da OCDE/PISA é usada também a expressão "literacia matemática", a qual foi escolhida de forma que enfatize o conhecimento matemático colocado em uso funcional numa multitude de situações diferentes. Para esse uso ser possível e viável, são necessárias capacidades e conhecimentos matemáticos fundamentais. Usar e envolver-se com a matemática implica não só o usar a matemática para formular, interpretar e resolver problemas numa variedade de contextos, mas também um amplo envolvimento pessoal por meio do comunicar, relacionar, avaliar e apreciar e gostar da matemática.

Assim, literacia matemática é a capacidade de um indivíduo identificar e compreender o papel que a matemática desempenha no mundo, para fazer juízos de valor matemáticos bem fundamentados e para se envolver com a matemática de maneiras que vão de encontro às suas necessidades, presentes e futuras, enquanto cidadão construtivo, preocupado e reflexivo (OCDE, 2003).

Nesse enquadramento, a literacia matemática envolve três componentes ou dimensões: (1) as situações ou contextos em que os problemas são estabelecidos; (2) o conteúdo matemático que deve ser usado para resolver os problemas, organizado em grandes ideias ou ideias abrangentes; e (3) as competências que devem ser activadas de forma que relacione o mundo real, no qual os problemas são gerados, 
com a matemática e, depois, resolva o problema. Essas três dimensões são de diferente natureza. As situações ou contextos definem as áreas de problemas do mundo real. Por seu turno, as grandes ideias reflectem a maneira segundo a qual se olha para o mundo com "óculos matemáticos". A dimensão das competências constitui o âmago da literacia matemática; são elas:

1. Pensar e raciocinar: inclui colocar questões características da matemática (por exemplo: Há $[\ldots]$, se sim, quantos? Como descobrimos [...]?); conhecer os tipos de respostas que a matemática fornece para essas questões; distinguir diferentes tipos de afirmações (definições, teoremas, conjecturas, hipóteses, asserções condicionais) e compreender e lidar com a extensão e os limites de determinados conceitos matemáticos.

2. Argumentar: envolve conhecer o que são as provas matemáticas e como diferem de outros tipos de raciocínio matemático; avaliar argumentos matemáticos de diferentes tipos; ter gosto e sensibilidade para as heurísticas (por exemplo: o que pode, ou não pode, acontecer e por quê? $\mathrm{O}$ que sabemos? $\mathrm{O}$ que queremos obter?) e construir e expressar argumentos matemáticos.

3. Comunicar: compreende expressar-se, de diferentes formas, sobre assuntos com conteúdo matemático, num formato oral ou escrito, e compreender as afirmações feitas por outros, por escrito ou oralmente, sobre tais assuntos.

4. Modelar: envolve estruturar o campo ou situação a ser modelada; traduzir a "realidade" em estruturas matemáticas; interpretar modelos matemáticos em termos da "realidade"; trabalhar com um modelo matemático; validar o modelo; reflectir, analisar e avaliar o modelo e os seus resultados; comunicar sobre o modelo e os seus resultados (incluindo as limitações de tais resultados); e monitorar e controlar o processo de modelação.

5. Formular e resolver problemas: inclui colocar, formular e definir diferentes tipos de problemas matemáticos (por exemplo: "puros", "aplicados", "abertos" e "fechados") e resolver diferentes tipos de problemas matemáticos de várias maneiras.

6. Representar: integra descodificar e codificar, traduzir, interpretar e distinguir diferentes formas de representação de situações e objectos matemáticos e as relações entre os vários tipos de representação; seleccionar e mudar diferentes formas de representação de acordo com a situação e o propósito.

7. Usar linguagem simbólica, formal ou técnica e operações: envolve descodificar e interpretar linguagem simbólica e formal e compreender as suas relações com a linguagem corrente; traduzir da linguagem corrente para linguagem simbólica/formal; lidar com afirmações e expressões que contêm símbolos e fórmulas; manipular variáveis, resolver equações e fazer cálculos.

8. Usar ajudas e ferramentas: envolve conhecer e ser capaz de usar várias ajudas e ferramentas, incluindo tecnologias de informação, que podem apoiar a actividade matemática; também inclui o reconhecer as limitações de tais ajudas e ferramentas. 
Apesar de listadas individualmente, existe considerável sobreposição entre as competências mencionadas. Além disso, ao usar a matemática, é, por norma, necessário mobilizar simultaneamente várias dessas competências (OCDE, 2003).

\section{PENSAMENTO CRÍTICO}

O trabalho realizado, por diferentes autores, procurando circunscrever a natureza particular do pensamento crítico, conduziu (e continua a conduzir) a uma multitude de perspectivas e conceptualizações.

McPeck $(1981,1990)$ associa pensamento crítico e cepticismo. O autor define pensamento crítico como "o uso apropriado de cepticismo reflexivo no âmbito de um problema de determinada área em consideração” (McPeck, 1990, p. 9, tradução nossa). Para ele, as áreas de problemas são as disciplinas, e o pensamento pode apenas ser julgado pelas normas particulares de uma disciplina. O recurso a um cepticismo reflexivo visa estabelecer razões apropriadas em virtude de normas epistemológicas. $\mathrm{Na}$ visão de McPeck, sobressai, portanto, uma dimensão normativa da área de saber em causa como definidora do pensar de forma crítica. Assim sendo, o pensamento crítico varia necessariamente de domínio para domínio e não pode ser perspectivado como um conjunto de capacidades gerais transferíveis para qualquer contexto.

Segundo Ennis (1985), a expressão "pensamento crítico" é geralmente usada querendo significar uma actividade prática e reflexiva, cuja meta é uma crença ou uma acção sensata. Para o autor, há cinco termos-chave - "prática", "reflexiva", "sensata", "crença" e "acção" - que se podem combinar na seguinte definição: "O pensamento crítico é uma forma de pensamento racional, reflexivo, focado no decidir em que acreditar ou o que fazer" (idem, p. 46, tradução nossa).

Assim definido, o pensamento crítico envolve tanto disposições, que dizem respeito aos aspectos mais afectivos, como capacidades, que se referem aos aspectos mais cognitivos. $\mathrm{O}$ conjunto de disposições de pensamento crítico traduz o que o autor designa por espírito crítico, isto é, uma tendência, compromisso ou inclinação para agir de forma crítica. Incluem: procurar estar bem informado, utilizar e mencionar fontes credíveis, procurar razões, procurar alternativas, ter abertura de espírito e procurar tanta precisão quanta o assunto o permitir.

As capacidades de pensamento crítico listadas por Ennis $(1987,1996)$, na sua definição operacional de pensamento crítico, estão organizadas em cinco áreas: clarificação elementar, suporte básico, inferência e clarificação elaborada e uma área de estratégias e tácticas. Cada uma dessas áreas inclui um compósito de capacidades de pensamento crítico agrupadas em diferentes categorias interdependentes.

A área de clarificação elementar integra as capacidades de pensamento crítico: focar uma questão; fazer e responder a questões de clarificação e/ou desafio; e analisar argumentos. Cada uma dessas capacidades inclui várias capacidades. Assim, por exemplo, "analisar argumentos" envolve: identificar conclusões; identificar as razões enunciadas; identificar as razões não enunciadas; e resumir. A área de suporte básico inclui as capacidades de pensamento crítico: avaliar a credibilidade de uma fonte; e fazer e avaliar observações. A área de inferência compreende três capaci- 
dades básicas de pensamento crítico que correspondem a três tipos de inferência: inferência indutiva, inferência dedutiva e inferência por juízo de valor.

A título ilustrativo, a inferência indutiva integra capacidades de pensamento crítico como: generalizar; e inferir conclusões e hipóteses explicativas. Essa última capacidade envolve capacidades como: delinear investigações, incluindo o planeamento do controlo de variáveis; procurar evidência e contraevidência; e procurar outras explicações possíveis. No âmbito da área de clarificação elaborada surgem as capacidades de pensamento: definir termos e avaliar definições; e identificar assunções.

A área de estratégias e tácticas inclui as capacidades: decidir uma acção; e interactuar com os outros. Decidir uma acção envolve, nomeadamente, definir o problema; seleccionar critérios para avaliar possíveis soluções; formular soluções alternativas; e controlar o processo de tomada de decisão. Por sua vez, interactuar com os outros abarca: empregar e reagir a denominações falaciosas (como, por exemplo, apelo à autoridade, apelo à tradição e circularidade); e apresentar uma posição a uma determinada audiência.

A propósito de algumas capacidades, Ennis salienta o uso de normas ou critérios para garantir o uso eficaz de tais capacidades e, por conseguinte, da qualidade do pensamento. No caso, por exemplo, da capacidade "avaliar a credibilidade de uma fonte", são apontados critérios como: perita/conhecedora/versada, reputação, conflito de interesses e acordo entre as fontes.

A respeito da capacidade "fazer e avaliar observações", são referidos critérios relacionados com: características do observador; características das condições de observação; e características do relato de observação. No âmbito da capacidade "inferir conclusões e hipóteses explicativas", integrada na inferência por indução, são apontados os critérios: explicar a evidência; ser consistente com os factos conhecidos; eliminar conclusões alternativas; e ser plausível.

Siegel (1989) define pensamento crítico como um tipo de pensamento que é apropriadamente movido por razões. Para o autor, o pensamento crítico possui duas componentes ou dimensões: avaliação de razões e espírito crítico. A componente de avaliação de razões significa que o pensador crítico deve ser capaz de avaliar razões e justificar, adequadamente, crenças, afirmações e acções. A dimensão espírito crítico quer dizer que o pensador crítico deve valorizar o bom pensamento e estar disposto a actuar de acordo com um pensamento de qualidade.

Assim, um pensador crítico deve não só ser capaz de avaliar a força das razões, para agir numa determinada direcção, com base em princípios, mas também estar disposto a fazê-lo. Os princípios que guiam a avaliação de razões podem ser de dois tipos: princípios específicos de um domínio (dependentes do conteúdo) e princípios gerais, passíveis de serem aplicados em diferentes contextos (por exemplo, princípios de lógica dedutiva e indutiva).

O respeito por normas e princípios do bom pensamento não pode ser simplesmente o resultado de habituação; ao contrário, deve ser baseado no reconhecimento do valor do pensamento crítico, isto é, da sua importância em promover 
crenças e acções responsáveis. Tal implica uma reflexão sobre a relevância e adequação de princípios do pensamento que estão a ser usados num caso particular.

Lipman (1991) foca a sua concepção de pensamento crítico na noção de julgamento, definindo o pensamento crítico como pensamento que facilita o julgamento porque se baseia em critérios. Os critérios são entendidos como as razões que suportam a objectividade de um juízo. Em virtude do domínio do saber em causa, poder-se-ão considerar como critérios apropriados, por exemplo, a utilidade, a segurança, a beleza, a coerência e/ou a pertinência.

$\mathrm{Na}$ perspectiva do autor, o desenvolvimento do pensamento crítico exige o uso de capacidades de pensamento ligadas aos processos de investigação, raciocínio, organização e transposição de informação. Tais capacidades de pensamento incluem: formular conceitos de forma precisa; operacionalizar conceitos; construir definições para palavras familiares; formular questões; exemplificar; reconhecer falácias; identificar e usar critérios (para, por exemplo, construir definições e para fazer juízos de valor); reconhecer consistências e contradições; identificar assunções; fornecer razões; fazer inferências; formular alternativas; analisar valores e considerar diferentes perspectivas.

A ideia de que o pensamento crítico envolve várias dimensões, designadamente uma dimensão normativa, é comum a outros autores. Para Paul (1993,2005), o pensamento crítico é uma forma de pensamento disciplinado e autodirigido, em que o pensador crítico sistemática e intencionalmente: desenvolve atitudes; toma consciência dos processos de pensamento; impõe critérios intelectuais ao pensamento; e avalia a eficácia do processo de pensamento tendo em conta o propósito e os critérios intelectuais.

Essa visão sobre o pensamento crítico releva três dimensões inter-relacionadas: atitudes, normas e processos de pensamento. A dimensão das atitudes ou valores intelectuais diz respeito aos traços de carácter necessários à acção enraizada na lógica e na razão e incluem: a humildade intelectual; a coragem intelectual; a empatia intelectual; a integridade intelectual; a perseverança intelectual; a confiança nas razões e a imparcialidade ou equidade. A dimensão normativa inclui critérios fundamentais considerados indispensáveis para o uso eficaz dos processos do pensamento, tais como: clareza, exactidão, precisão, relevância, profundidade e consistência. A dimensão dos processos de pensamento inclui: propósito ou meta; questão ou problema a resolver; ponto de vista, perspectiva ou quadro de referência; dados, informação e evidência; conceitos e ideias; assunções; implicações e consequências; e inferências.

Na perspectiva de Halpern (1996), o pensamento crítico é o uso das capacidades ou processos cognitivos que aumentam a probabilidade de se obter resultados desejáveis. Assim, o pensamento crítico é intencional, racional e dirigido para uma meta, podendo essa meta ser a resolução de um problema ou uma tomada de decisão. O pensamento crítico também envolve avaliação, pois, quando se pensa criticamente, está-se a avaliar os resultados do processo de pensamento, isto é, quanto boa é uma decisão ou quanto bem foi um problema resolvido. Nesse quadro, o tipo de 
pensamento subjacente a hábitos diários mecanizados também não está incluído no pensamento crítico. Isso porque, apesar de estar dirigido para uma meta, envolve pouca avaliação consciente. Seguir o caminho habitual para a escola é exemplo de pensamento não dirigido ou automático.

Autores como Bailin (2002) e Angeli eValanides (2005) salientam a dimensão normativa do pensamento crítico, considerando ser esta que governa a qualidade do pensamento e do juízo de valor numa determinada área; para pensar criticamente é necessário conhecer e actuar de acordo com tais critérios ou normas. Alguns dos critérios ou normas que distinguem o pensamento crítico do não crítico incluem: fiabilidade dos dados, controlo de variáveis, credibilidade de fontes de informação e validade das inferências.

\section{CONEXÕES DE LITERACIA CIENTÍFICA, LITERACIA MATEMÁTICA E PENSAMENTO CRÍTICO E EMERGÊNCIA DE UM QUADRO DE REFERÊNCIA}

Como corolário do exposto e decorrente da análise interpretativa feita pelos autores do presente artigo, no quadro seguinte evidenciam-se pontos de convergência entre conceptualizações acerca de literacia científica, literacia matemática e pensamento crítico. Clarifique-se que a expressão "literacia matemática" é por nós aqui usada de forma inclusiva, porquanto sob essa designação são também contempladas perspectivas de autores que usam outras expressões como "literacia quantitativa" e "numeracia". De forma abrangente e aglutinadora, tendo em consideração a revisão efectuada sobre o assunto, tomam-se como referência as dimensões: (1) conteúdo; (2) processos/capacidades de pensamento e (3) disposições/atitudes e valores. Assim, apresenta-se, de seguida, uma síntese descritiva de tais dimensões.

\section{Quadro 1 - Síntese descritiva das dimensões envolvidas na literacia científica, na literacia matemática e no pensamento crítico}

\begin{tabular}{|c|c|c|}
\hline \multicolumn{3}{|c|}{ Dimensão: Conteúdo } \\
\hline Literacia Científica & Literacia Matemática & Pensamento Crítico \\
\hline $\begin{array}{l}\text { - termos/vocabulário e conceitos base; } \\
\text { - grandes ideias e explicações } \\
\text { científicas; } \\
\text { - normas e processos de } \\
\text { investigação científica; } \\
\text { - modo como se desenvolve a } \\
\text { actividade científica; } \\
\text { - natureza do conhecimento } \\
\text { científico; } \\
\text { - natureza do trabalho dos cientistas, } \\
\text { incluindo a dimensão ética; } \\
\text { - inter-relações ciência/tecnologia/ } \\
\text { sociedade, incluindo o papel } \\
\text { dos cientistas na sociedade e em } \\
\text { processos de tomada de decisão; } \\
\text { - relações ciência/matemática; } \\
\text { - história da ciência. }\end{array}$ & $\begin{array}{l}\text { - termos/vocabulário, conceitos, } \\
\text { operações e relações; } \\
\text { - sentido do número; } \\
\text { - sentido do símbolo; } \\
\text { - ideias importantes (conexões); } \\
\text { - natureza da matemática; } \\
\text { - história da matemática; } \\
\text { - papel da matemática na } \\
\text { investigação científica, nos avanços } \\
\text { tecnológicos e na compreensão de } \\
\text { assuntos do domínio público. }\end{array}$ & $\begin{array}{l}\text { - termos/vocabulário (por exemplo, } \\
\text { condições necessárias e suficientes; } \\
\text { correlação e causa; hipótese); } \\
\text { - conhecimento conceptual e } \\
\text { axiológico do domínio subjacente à } \\
\text { questão ou problema sobre o qual } \\
\text { incide o pensar de forma crítica. }\end{array}$ \\
\hline
\end{tabular}


(...continuação)

\begin{tabular}{|c|c|c|}
\hline \multicolumn{3}{|c|}{ Dimensão: Processos/Capacidades de Pensamento } \\
\hline Literacia Científica & Literacia Matemática & Pensamento Crítico \\
\hline $\begin{array}{l}\text { - tomar decisões; } \\
\text { - resolver problemas; } \\
\text { - argumentar com base em } \\
\text { evidência científica; } \\
\text { - assumir e expressar posições } \\
\text { fundamentadas em conhecimento } \\
\text { científico; } \\
\text { - recolher, analisar e avaliar } \\
\text { informação e evidência; } \\
\text { - comunicar, nomeadamente, } \\
\text { conclusões baseadas em evidência } \\
\text { científica, conclusões alternativas, as } \\
\text { implicações societais de conclusões } \\
\text { científicas; } \\
\text { - fornecer razões contra ou a favor } \\
\text { de uma dada conclusão; } \\
\text { - identificar assunções para chegar } \\
\text { a uma dada conclusão; } \\
\text { - interpretar textos de divulgação } \\
\text { científica e discutir a validade das } \\
\text { conclusões neles apresentadas; } \\
\text { - avaliar informação científica com } \\
\text { base na credibilidade das fontes e } \\
\text { na validade dos métodos usados } \\
\text { para a gerar; } \\
\text { - descrever, explicar e fazer } \\
\text { previsões; } \\
\text { - identificar questões, incluindo } \\
\text { questões que podem ser } \\
\text { investigadas cientificamente; } \\
\text { - identificar evidência necessária } \\
\text { numa investigação científica (por } \\
\text { exemplo, variáveis a controlar); } \\
\text { - formular e testar hipóteses; } \\
\text { - interpretar evidência científica e } \\
\text { tirar conclusões; } \\
\text { - aplicar procedimentos de } \\
\text { metodologia científica. }\end{array}$ & $\begin{array}{l}\text { - tomar decisões; } \\
\text { - resolver problemas, incluindo } \\
\text { formular problemas, planear e testar } \\
\text { diferentes estratégias, justificar } \\
\text { soluções e processos de resolução; } \\
\text { - construir e expressar argumentos } \\
\text { matemáticos; } \\
\text { - analisar e avaliar argumentos } \\
\text { matemáticos; } \\
\text { - explicar, justificar e reflectir sobre } \\
\text { argumentos matemáticos; } \\
\text { - comunicar informação numérica; } \\
\text { - expressar-se, de diferentes formas, } \\
\text { sobre assuntos com conteúdo } \\
\text { matemático; } \\
\text { - fazer juízos de valor matemáticos } \\
\text { bem fundamentados; } \\
\text { - interpretar informação } \\
\text { apresentada de diferentes formas; } \\
\text { - recolher e analisar evidência; } \\
\text { - identificar padrões e relações; } \\
\text { - detectar falácias; } \\
\text { - questionar assunções; } \\
\text { - fazer conjecturas; } \\
\text { - fazer generalizações com rigor; } \\
\text { - formular e testar hipóteses; } \\
\text { - tirar conclusões lógicas a partir } \\
\text { de dados; } \\
\text { - reconhecer níveis de rigor usados } \\
\text { em inferências; } \\
\text { - construir e alternar entre } \\
\text { diferentes tipos de representação; } \\
\text { - manipular variáveis; } \\
\text { - executar procedimentos de forma } \\
\text { flexível, apropriada, precisa e eficaz. }\end{array}$ & $\begin{array}{l}\text { - tomar decisões; } \\
\text { - formular, de forma clara e precisa, } \\
\text { a questão ou problema a resolver; } \\
\text { - estabelecer razões apropriadas } \\
\text { (em virtude de normas } \\
\text { epistemológicas); } \\
\text { - avaliar razões (com base em } \\
\text { princípios racionais); } \\
\text { - analisar e avaliar argumentos; } \\
\text { - argumentar e contra-argumentar; } \\
\text { - procurar diferentes pontos } \\
\text { de vista e identificar as suas } \\
\text { potencialidades e limitações; } \\
\text { - avaliar imparcialmente todos os } \\
\text { pontos de vista; } \\
\text { - identificar assunções e avaliar a } \\
\text { sua provável validade; } \\
\text { - identificar falácias; } \\
\text { - avaliar a credibilidade de uma } \\
\text { fonte (com base em critérios como: } \\
\text { versada, reputação, conflito de } \\
\text { interesses); } \\
\text { - fazer generalizações (tendo } \\
\text { em conta, nomeadamente, a } \\
\text { constituição da amostra); } \\
\text { - formular hipóteses; } \\
\text { - tirar conclusões (tendo em conta } \\
\text { critérios como explicar a evidência, } \\
\text { ser consistente com factos } \\
\text { conhecidos, ser plausível e eliminar } \\
\text { conclusões alternativas); } \\
\text { - procurar inferências que são } \\
\text { profundas, consistentes e lógicas; } \\
\text { - identificar as potencialidades } \\
\text { relativas de uma inferência; } \\
\text { - ligar as inferências, forte e } \\
\text { directamente, da evidência às } \\
\text { conclusões; } \\
\text { - investigar, incluindo o } \\
\text { planeamento do controlo efectivo } \\
\text { de variáveis); } \\
\text { - fazer juízos de valor (tendo } \\
\text { em consideração, por exemplo, } \\
\text { consequências de acções propostas, } \\
\text { soluções alternativas); } \\
\text { - analisar e avaliar crenças e cursos } \\
\text { de acção; } \\
\text { - avaliar o processo de pensamento } \\
\text { proma). }\end{array}$ \\
\hline
\end{tabular}

(continua...) 
(...continuação)

\begin{tabular}{|c|c|c|}
\hline \multicolumn{3}{|c|}{ Dimensão: Disposições/Atitudes e Valores } \\
\hline Literacia Científica & Literacia Matemática & Pensamento Crítico \\
\hline $\begin{array}{l}\text { - apreciação da ciência; } \\
\text { - interesse pela ciência; } \\
\text { - autoconfiança no uso da ciência; } \\
\text { - procurar estar bem informado; } \\
\text { - abertura de espírito; } \\
\text { - atitude interrogativa; } \\
\text { - respeito pela evidência; } \\
\text { - respeito ético; } \\
\text { - flexibilidade para aceitar o erro e } \\
\text { a incerteza; } \\
\text { - seriedade no trabalho; } \\
\text { - rigor e precisão; } \\
\text { - coerência; } \\
\text { - cepticismo; } \\
\text { - perseverança. }\end{array}$ & $\begin{array}{l}\text { - apreciar e gostar da matemática; } \\
\text { - disposição para ver a matemática } \\
\text { como uma disciplina sensível e útil } \\
\text { em múltiplos contextos; } \\
\text { - confiança para fazer matemática; } \\
\text { - à vontade com a matemática; } \\
\text { - envolver-se com a matemática } \\
\text { (fazer e usar a matemática numa } \\
\text { variedade de contextos e situações). }\end{array}$ & $\begin{array}{l}\text { - autoconfiança no uso das } \\
\text { capacidades para pensar de forma } \\
\text { crítica; } \\
\text { - atitude inquiridora; } \\
\text { - abertura de espírito; } \\
\text { - procurar estar bem informado; } \\
\text { - procurar tanta precisão quanta o } \\
\text { assunto o permitir; } \\
\text { - confiança e respeito pelas razões; } \\
\text { - humildade intelectual; } \\
\text { - coragem intelectual; } \\
\text { - empatia intelectual; } \\
\text { - integridade intelectual; } \\
\text { - perseverança intelectual; } \\
\text { - imparcialidade ou equidade. }\end{array}$ \\
\hline
\end{tabular}

Fonte: Elaboração dos autores.

Dessa síntese descritiva sobressai, no nível do conteúdo, uma ênfase em "grandes ideias" e não em factos isolados, bem como uma ênfase nas conexões entre ideias da mesma área (ciências ou matemática), entre ideias científicas e ideias matemáticas e entre estas e o mundo real. Dentro dessa perspectiva, salienta-se a contextualização histórica e social do conhecimento científico e matemático, procurando romper com uma visão da ciência e da matemática como actividades desligadas de valores éticos e morais e de interesses e influências sociais e políticas.

A educação em ciências e em matemática, numa perspectiva de literacia, deve proporcionar a (re)construção de conhecimentos úteis e com significado social que resultem significativos e funcionais para a vida. Nesse sentido, o conhecimento construído deve constituir um instrumento para a tomada de consciência acerca dos problemas do mundo e para a compreensão das realidades quotidianas e, sobretudo, para a actuação sobre elas. Mas, uma actuação no sentido desejado - o bem da humanidade, isto é, da cultura da paz, da tolerância e do desenvolvimento das pessoas e dos povos que permita melhor qualidade de vida para todos e um ambiente sustentável para as gerações actuais e futuras - requer, em simultâneo, outras ferramentas, entre as quais se encontram as capacidades de pensamento e as disposições/atitudes de pensamento crítico.

Com efeito, denota-se, na perspectiva dos autores, uma ampla interdependência e sobreposição entre a literacia científica, a literacia matemática e o pensamento crítico no que diz respeito às capacidades e às disposições/atitudes e valores envolvidos. Tal apoia a tese que sustenta que o pensamento crítico está incorporado numa família de modos de pensar que se intersectam, entre os quais se encontram o pensamento científico e o pensamento matemático. A esse propósito, na "Declaração sobre a ciência e a utilização do conhecimento científico", adoptada pela Conferência Mundial sobre a Ciência (UNESCO/International Council for Science [ICSU], 1999), é referido que a essência do pensamento científico é a ca- 
pacidade de examinar problemas de diferentes perspectivas e procurar explicações dos fenómenos naturais e sociais, submetendo-as constantemente a um pensamento crítico e livre, que é essencial num mundo democrático.

Muitas das capacidades de pensamento inerentes à literacia científica e à literacia matemática correspondem a capacidades de pensamento crítico. Tanto a literacia científica como a literacia matemática envolvem capacidades de tomada de decisão e de resolução de problemas. Assumindo a posição de autores como Ennis e Norris (1989), o pensamento crítico envolve a resolução de problemas e a tomada de decisão, pois o pensamento crítico ocorre num contexto de resolução de problemas e/ou num contexto de interacção com os outros, a fim de decidir, racionalmente, o que fazer ou em que acreditar. Os processos próprios da ciência e da matemática ajudam na elaboração de juízos no quadro de situações de resolução de problemas e de interacção com os outros.

No seguimento dessa ideia, na intersecção entre literacia científica, literacia matemática e pensamento crítico surgem outras capacidades, tais como: argumentar; avaliar a credibilidade das fontes; avaliar a evidência disponível e ir além do seu imediato e aparente valor, adoptando uma perspectiva questionadora; analisar e avaliar argumentos; identificar falácias e assunções subjacentes a uma dada posição; considerar, comparar e pesar alternativas. No mesmo sentido, configuram-se como disposições: procurar estar bem informado, respeito pelo uso da evidência, cepticismo na avaliação de asserções, honestidade intelectual e abertura de espírito.

A permear as diferentes dimensões de literacia científica, literacia matemática e pensamento crítico encontram-se normas e critérios tendentes a assegurar a qualidade do processo de pensamento crítico em contextos e domínios específicos de ciência e matemática regidos, eles próprios, também, por critérios e normas. Tais normas ou critérios comuns incluem: a precisão, a clareza, a consistência, a credibilidade das fontes, o controlo de variáveis e a validade das inferências.

O exposto em conjugação com o esquema-síntese, construído pelos autores deste artigo e a seguir apresentado, configura-se como um quadro conceptual acerca da literacia científica, literacia matemática e pensamento crítico. Releva elementos emergentes na intersecção de componentes ou dimensões comuns à literacia científica, literacia matemática e pensamento crítico, em estreita relação com a ideia de mobilização intrincada de tais elementos, de modo que se possam constituir em saberes, em acção ou em uso no âmbito de diversos contextos e situações do quotidiano, desde o acompanhar o sentido de uma notícia, ler e compreender um artigo de divulgação científica, escrever e comunicar com os outros acerca de questões que envolvem a ciência e/ou a matemática - passando pela tomada de decisão e resolução de problemas pessoais sobre, por exemplo, dieta e alimentação - até à resolução de problemas e participação na tomada de decisão sobre questões públicas como, por exemplo, saúde pública e protecção ambiental. 

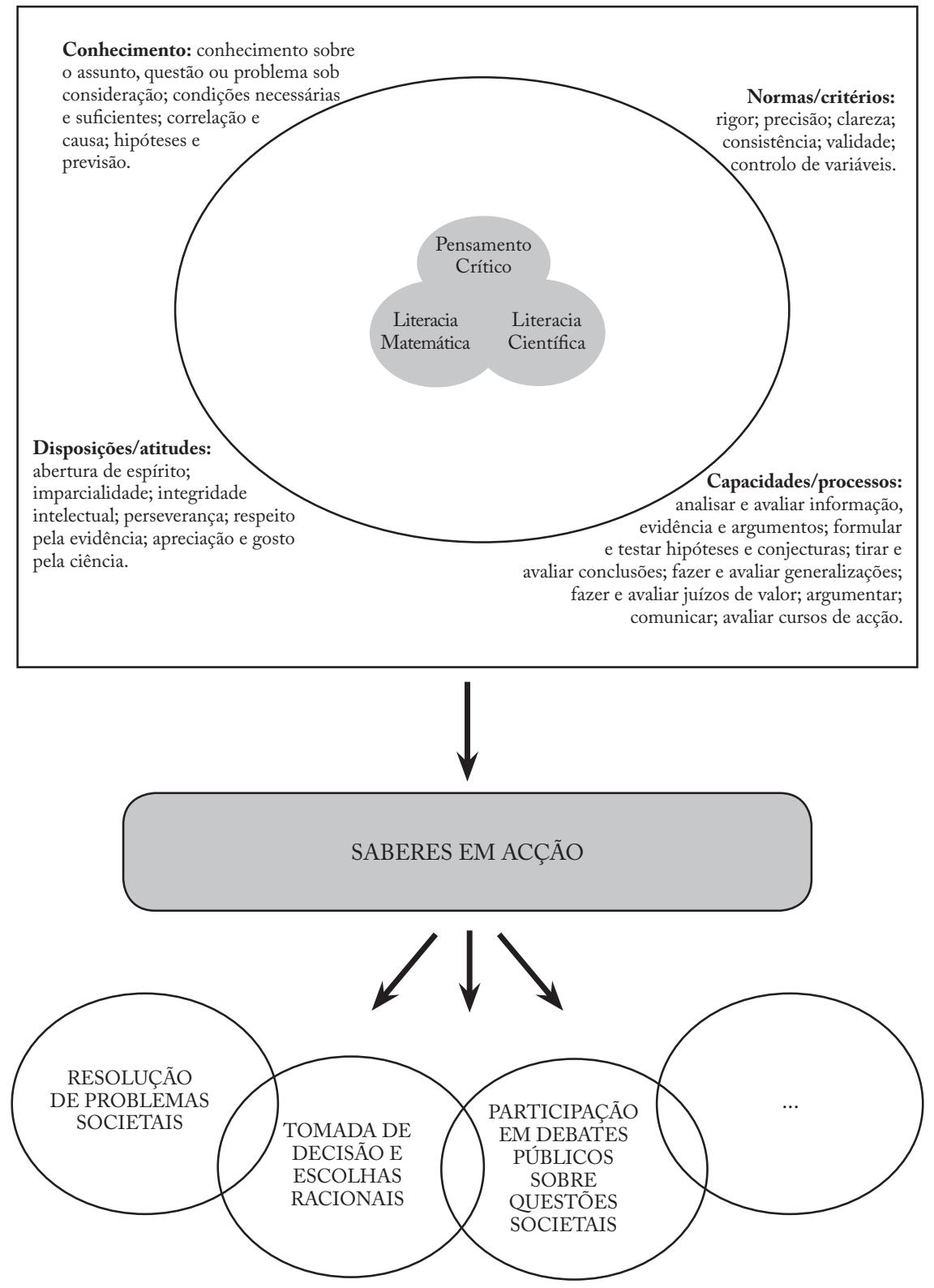

\section{EXERCÍCIO CIDADANIA ACTIVA INFORMADA E RESPONSÁVEL}

Figura 1 - Esquema-síntese conceptual acerca da literacia científica, literacia matemática e pensamento crítico. Fonte: Elaboração dos autores. 


\section{CONSIDERAÇÕES FINAIS}

No mundo contemporâneo, e em particular nas sociedades democráticas, a literacia científica, a literacia matemática e o pensamento crítico afiguram-se como cruciais para a autonomia e qualidade de vida de cada pessoa, para o desenvolvimento do país, assim como para fomentar a responsabilidade social e melhorar a participação dos cidadãos na tomada de decisões e na resolução de problemas de âmbito local, regional, nacional ou mundial.

De facto, em muitos países, defende-se e preconiza-se, hoje, que o ensino das ciências e da matemática nos ensinos básico e secundário deve reger-se por princípios que promovam o pensamento crítico, a literacia científica e a literacia matemática de todos os alunos. Promover a literacia de todas as pessoas é, desde logo, incompatível com a finalidade exclusivamente propedêutica do ensino das ciências; isto é, com uma ciência escolar relevante só para prosseguimento de estudos e carreiras científicas. Nessa linha, equacionam-se finalidades da educação em ciências e em matemática socialmente orientadas e mais centradas no aluno, uma vez que se trata de formar cidadãos que, reconhecendo a ciência e a matemática como empreendimentos humanos que fazem parte integrante da cultura, sejam capazes de mobilizar os saberes na vida diária e no trabalho e de intervir socialmente, de forma crítica, nas tomadas de decisão.

- Nesse enquadramento, o referencial apresentado, focado na literacia científica, na literacia matemática e no pensamento crítico, pode ser usado para orientar a formação de professores, a produção de materiais didácticos e o desenvolvimento de práticas de ensino das ciências e da matemática, o desenvolvimento de práticas mais consonantes com metas de literacia.

- Afigura-se como passível de ser usado para delinear situações, para vivenciar a participação/acção, capazes de despoletar a necessidade de (re)construir e desenvolver, de forma integrada, conhecimentos, capacidades de pensamento e disposições no quadro da formação de cidadãos activos e agentes de coesão social numa sociedade democrática plural, científica e tecnologicamente avançada.

- O desenvolvimento e operacionalização de tais situações devem, pois, pautar-se pelo criar de múltiplas oportunidades para os alunos (re)construírem conhecimento, desenvolverem atitudes e capacidades de pensamento crítico. Tal requer, nomeadamente, o criar e sustentar um ambiente de aprendizagem que estimule os alunos a expressar e a defender as suas ideias, a explorar, a assumir riscos, a partilhar sucessos e insucessos e a questionarem-se mutuamente. Exige também o dar tempo aos alunos para pensarem e experimentarem por si próprios e o fomentar e alimentar a discussão e a reflexão sobre a acção com base em questões provocativas do pensamento, emergentes do referencial apresentado no presente artigo.

- A título ilustrativo, no contexto da escrita de artigos de posições e/ou debates sobre questões societais controversas, poder-se-á confrontar os alunos com questões como: "O que achas que vai acontecer a seguir?", "Isto acontece 
sempre ou só algumas vezes?", "O que se aplica a estes casos e a outros similares?", "Como justificas as relações que estabeleceste?", "O que te leva a pensar que essas relações se verificam sempre?", "Por que razão(ões) tal acontece?", "Que razões suportam a conclusão?", "A conclusão/tese é consistente com os factos/evidências apresentadas?", "Como sabes que esta resposta é correcta (adequada)?" " "O que te leva a crer que isso é verdade?".

A fim de potenciar as oportunidades para os alunos mobilizarem conhecimento, atitudes e capacidades de pensamento crítico ligadas à literacia científica e matemática, é essencial perscrutar o pensamento dos alunos com sucessivas questões e, quando oportuno, fornecer informação relevante que ajude os alunos a atingir respostas mais elaboradas e profundas. Importa também criar e sustentar uma atmosfera de sala de aula caracterizada pela empatia, aceitação e abertura de espírito, em que todos os alunos possam sentir que os seus contributos são considerados e aberta e seriamente discutidos.

\section{REFERÊNCIAS}

Angeli, Charoule; Valanides, Nicos. A conceptual framework for scaffolding critical thinking in an online conference for a science education methods course.In: KommERs, Piet; Richards, Griff (Eds.). Proceedings of World Conference on Educational Multimedia, Hypermedia and Telecommunications 2005. Chesapeake: AACE, 2005.

AAAS. Benchmarks for science literacy. Washington, DC: AAAS, 1993. . Atlas of science literacy - Project 2061. Washington, DC: AAAS, 2001.

BaILIN, Sharon. Critical thinking and science education. Science $\mathcal{E}$ Education, Netherlands, Kluwer Academic Publishers, v. 11, n. 4, p. 361-375, jul. 2002.

BeLL, Randy et al. Just do it? Impact of a science apprenticeship program on high school students' understandings of the nature of science and scientific inquiry. Journal of Research in Science Teaching, Malden, MA (USA), John Wiley \& Sons, v. 40, n. 5, p. 487-509, may 2003.

Brewer, Carol. Scientific literacy in the classroom. Estados Unidos: American Institute of Biological Sciences, 2008.

B Rown, Margaret. Effective teaching of numeracy. In: Koshy, Valsa et al. (Eds.). Mathematics for primary teachers. London: Routledge, 2000. p. 149-157.

Byвee, Rodger. The contemporary reform of science education. In: Rнотоn, Jack; Bowers, Patricia (Eds.). Issues in science education. Arlington: National Science Teachers Association, 1996. p. 1-14.

Comissão Europeia. Europeans, science and technology. 2005. Disponível em: <http:// ec.europa.eu/public_opinion/archives/ebs/ebs_224_report_en.pdf>.Acesso em:jul.2007. DeBoer, George E. Scientific literacy: another look at its historical and contemporary meanings and its relationship to science education reform. Journal of Research in Science Teaching, Malden, MA (USA), John Wiley \& Sons, v. 37, n. 6, p. 582-601, aug. 2000. 
EnNis, Robert Hugh. A logical basis for measuring critical thinking skills. Educational Leadership, Alexandria, VA (USA), Association for Supervision and Curriculum Development, v. 43, n. 2, p. 44-48, oct. 1985.

A taxonomy of critical thinking dispositions and abilities. In: Baron, Joan B; Sternberg, Robert J. (Eds.). Teaching thinking skills: theory and practice. New York: W. H. Freeman and Company, 1987.

. Critical thinking. Upper Saddle River: Prentice Hall, 1996.

.; Nor RIs, Stephen. Evaluating critical thinking. Pacific Grove: Critical Thinking Press \& Software, 1989.

Fullan, Michael; Earl, Lorna. United Kingdom national literacy and numeracy strategies. Journal of Educational Change, Netherlands, Kluwer Academic Publishers, v. 3, n. 1, p. 1-5, jan. 2002.

Halpern, Diane F. Thought and knowledge: an introduction to critical thinking. 3. ed. Mahwah: Lawrence Erlbaum Associates, 1996.

Harlen, Wynne. The assessment of scientific literacy in the OECD/PISA project. Studies in Science Education, London, Routledge, v. 36, n. 1, p. 79-104, 2001.

.Evaluar la alfabetización científica en el programa de la OECD para la evaluación internacional de estudantes (PISA). Enseñanza de las Ciencias, Barcelona, Universitat Autònoma de Barcelona, Institut de Ciències de l'Educación, v. 20, n. 2, p. 209-216, 2002.

.Developments in the assessment of scientific literacy in the OECD/PISA project. School Science Review, Hatfield (UK), The Association for Science Education, v. 85, n. 311, p. 91-98, dec. 2003.

Hurd, Paul DeHart. Scientific literacy: new minds for a changing world. Science Education, Malden, MA (USA), John Wiley \& Sons, v. 82, n. 3, p. 407-416, june 1998.

Irwin, Kathyn C.; Britt, Murray S. The algebraic nature of student's numerical manipulation in the New Zealand numeracy project. Educational Studies in Mathematics, Netherlands, Springer, v. 58, n. 2, p. 169-188, feb. 2005.

Kemp, Andrew. Implications of diverse meanings for "scientific literacy". In: CRAW Ford, Barbara A. (Ed.). Proceedings of the 2002 Annual International Conference of the Association of Teachers in Science. Pensacola: AETS, 2002.p.1.202-1.229. Disponível em: <http://www. edu.psu.edu/CI/journals/2002aets/s3_kemp.rtf>. Acesso em: jan. 2004.

KilPATRICK, Jeremy. Understanding mathematical literacy: the contribution of research. Educational Studies in Mathematics, Netherlands, Springer, v. 47, n. 1, p.101-116, may 2001. LAUgrsch, Rudiger C. Scientific literacy: a conceptual overview. Science Education, Malden, MA (USA), John Wiley \& Sons, v. 84, n. 1, p. 71-94, jan. 2000.

Lipman, Mathew. Thinking in education. Cambridge: Cambridge University Press, 1991. МсPеск, John Endsley. Critical thinking and education. Oxford: Martin Robertson, 1981. . Teaching critical thinking. New York: Routledge, 1990.

ME/DEB. Currículo nacional do ensino básico. Lisboa: Editorial do Ministério da Educação, 2001. 
Millar, Robin; Osborne, Jonathan. Beyond 2000: science education for the future. London: King's College, School of Education, 1998.

NCTM. Curriculum and evaluation standards for school mathematics. Reston, VA: NCTM, 1989.

. Principles and standards for school mathematics. Reston, VA: NCTM, 2000.

NRC. National science education standards. Washington, DC: National Academy Press, 1996.

OCDE. Measuring student knowledge and skills: the PISA assessment of reading, mathematical and scientific literacy. Paris: OCDE, 2000.

. The PISA 2003. Assessment framework - mathematics, reading, science, problem solving, knowledge and skills. Paris: OCDE, 2003.

. Evolution of student interest in science and technology studies. Organisation for Economic Co-operation and Development - Global Science Forum Policy Report, may 2006. Disponível em: <http://www.oecd.org/dataoecd/16/30/36645825.pdf>. Acesso em: set. 2009.

Paul, Richard W. Critical thinking - what every person needs to survive in a rapidly changing world. 3. ed. Santa Rosa: Foundation for Critical Thinking, 1993.

.The state of critical thinking today. New Directions for Community Colleges, Malden, MA (USA), John Wiley \& Sons, n. 130, p. 27-38, jun. 2005.

Pinto-Ferreira, Carlos; Serrão, Anabela; Padinha, Lídia. PISA 2006 - competências científicas dos alunos portugueses. Lisboa: GAVE, 2007.

Pugalee, David K.; Chamblee, Gregory E. Mathematical and technological literacy: developing an integrated $21^{\text {st }}$ century model. In: Annual Meeting of the Association of Mathematics Teacher Educators, 1999. Chicago: 1999.

Ramalho, Glória. Resultados do estudo internacional PISA 2000 - Programme for International Student Assessment. Lisboa: GAVE, 2001.

. Resultados do estudo internacional PISA 2000 - Programme for International Student Assessment. Lisboa: GAVE, 2004.

Rocard, Michael et al. (High Level Group on Science Education). Science education now: a renewed pedagogy for the future of Europe. Bruxelas: Comissão Europeia, 2007.

Rutherford, James; Ahlgren, Andrew. Ciência para todos. Tradução Catarina Caldeira Martins. Lisboa: Gradiva, 1990. (Tradução 1995).

Siegel, Harvey. The rationality of science, critical thinking, and science educaction. Synthese, Netherlands, Springer, v. 80, n. 1, p. 9-41, jul. 1989.

SJøвеRg, Svein. Scientific literacy and school science - arguments and second thoughs. In: .; Kallerud, Egil (Eds.). Science technology and citizenship. The public understanding of science and technology in science education and research policy. Oslo: Norwegian Institute for Studies in Research and Higher Education (NIFU), 1997. p. 9-28. Disponível em: <htpp://folk.uio.no/sveinsj/literacy.html>. Acesso em: jul 2005. 
Shamos, Morris Herbert. The myth of scientific literacy. New Brunswick: Rutgers University Press, 1995.

SteEn, Lynn Arthur. Numeracy: the new literacy for a data-drenched society. Educational Leadership, Alexandria, VA (USA), Association for Supervision and Curriculum Development, v. 57, n. 2, p. 8-13, oct. 1999.

et al.The case for quantitative literacy. In: SteEn, Lynn Arthur (Ed.). Mathematics and democracy. The case for quantitative literacy. Reston: National Council on Education and the Disciplines, 2001.

Swartz, Robert J.; Perkins, David N. Teaching thinking: issues \& approaches. Pacific Grove: Critical Thinking Press \& Software, 1990.

Unesco/ICSU. Ciência para o século XXI- um novo compromisso. Paris: UNESCO, 1999. Vieira, Rui Marques; Tenreiro-Vieira, Celina. Literacia científica, literacia matemática e pensamento crítico. Enseñanza de las Ciências, Barcelona, Universitat Autònoma de Barcelona, Institut de Ciències de l'Educació, v. 27, número extra do VIII Congreso Internacional sobre Investigación en Didáctica de las Ciências, p. 394-399, set. 2009. Disponível em: <http://ice.uab.cat/congresos2009/eprints/cd_congres/propostes_htm/ propostes/art-394-399.pdf >. Acesso em: nov. 2010.

.; Martins, Isabel Pinheiro. Pensamiento crítico y literacia científica. Alambique, Didáctica de las Ciencias Experimentales, Barcelona, Graó, v. 2010, n. 65, p. 96-103, jul./ set. 2010.

Zevenbergen, Robyn. Technologizing numeracy: intergenerational differences in working mathematically in new times. Educational Studies in Mathematics, Netherlands, Springer, v. 56, n. 1, p. 97-117, may 2004.

\section{SOBRE OS AUTORES}

Celina Tenreiro-Vieira é doutora em ciências da educação pela Universidade de Lisboa. Professora auxiliar convidada da Universidade de Aveiro. E-mail: cvieira@ua.pt

Rui Marques Vieira é doutor em didática pela Universidade de Aveiro. Professor auxiliar da mesma instituição.

E-mail: rvieira@ua.pt

Recebido em novembro de 2010

Aprovado em novembro de 2011 


\section{CELINA TENREIRO-VIEIRA E RUI MARQUES VIEIRA}

Literacia e pensamento crítico: um referencial para a educação em ciências e em matemática

É hoje amplamente defendida uma educação em ciências e em matemática, numa perspectiva de literacia, que habilite cada um a contribuir para a melhoria da qualidade de vida de todos e um ambiente sustentável para as gerações atuais e futuras. Nessa linha, em conjugação com o facto de o pensamento crítico emergir como proeminente e estreitamente ligado à literacia científica e matemática, o presente artigo centra-se em estudos desenvolvidos pelos autores com a finalidade de conferir clareza e inteligibilidade a esse campo, estabelecendo um referencial que possa ser usado para orientar a formação de professores e a educação em ciências e em matemática das crianças e jovens. O referencial aqui apresentado configura-se 
como um suporte à construção de ideias claras acerca de literacia científica, literacia matemática e pensamento crítico, passíveis de serem congruentemente plasmadas no desenvolvimento de materiais didáticos e de práticas pedagógico-didáticas intencional e fundamentadamente orientadas para o promover da literacia crítica dos alunos.

Palavras-chave: literacia científica; literacia matemática; pensamento crítico; formação de professores; educação em ciências e em matemática.

\section{Literacy and critical thinking: a framework for education in science and mathematics}

It is now widely advocated an education in science and mathematics with a perspective of literacy which enables every one to contribute to the improvement of the quality of life for all and to a sustainable environment for current and future generations. In this line, together with the fact that critical thinking emerges as prominent and closely linked to scientific literacy and numeracy, this article focuses on studies developed by its authors in order to bring clarity and intelligibility to this field, establishing a framework which can be used to guide teacher education and education in science and mathematics for children and young people. The framerwork presented here is configured as a support for teachers to construct clear ideas about scientific literacy / numeracy / critical thinking, which can be molded congruently in developing teaching materials and practices essentially oriented to promote students' critical literacy.

Keywords: scientific literacy; numeracy; critical thinking; teacher education; education in science and mathematics.

\section{Literacía y pensamiento crítico: un referencial para la educación en ciencias y matemáticas}

En la actualidad se aboga por una educación en ciencias y matemáticas con una perspectiva de alfabetización, que permita contribuir a mejorar la calidad de vida de cada uno de nosotros y de un medio ambiente sostenible para las generaciones actuales y futuras. En esta linea, junto con el hecho de que el Pensamiento Crítico (PC) emerge como un proceso preeminente y apuradamente vinculado a la literacía cientifica y matemática, el presente artículo se centra en los estudios realizados por los autores con el fin de aportar claridad e inteligibilidad a este campo, estableciendo un marco referencial que se pueda usar para guiar la formación del profesorado y la educación en ciencias y matemáticas para los niños y los jóvenes. El marco que se presenta aqui se configura como un apoyo para la construcción de ideas claras acerca de Literacía Cien tífica (LC)/Literacia Matemática (LM)/ Pensamiento Crítico (PM), capaces de ser coherentemente plasmadas en el desarrollo de materiales didácticos y de prácticas pedagógico-didácticas intencional y fundamentalmente orientadas a promover la literacía crítica de los estudiantes.

Palabras clave: literacía cientifica; literacía matemática; pensamiento crítico; formación de profesorado; educación en ciencias e en matemática. 